\title{
Valoração econômica de áreas de recreação: o caso do Parque Metropolitano de Pituaçu, Salvador, BA
}

\author{
Geneci Braz de Sousa ${ }^{1}$ \\ José Aroudo Mota ${ }^{2}$
}

Resumo: Nos centros urbanos, a criação e manutenção de espaços públicos destinados à preservação ambiental e aos usos de recreação e lazer tem sido um dos desafios enfrentados pelos gestores públicos. Localizado em uma área de expansão urbana de Salvador, o Parque Metropolitano de Pituaçu, contando com uma expressiva área verde destinada ao uso público, está sujeito a indicadores de risco ambiental, tornando-se um ativo natural frágil. O objetivo do presente estudo está em estimar o valor para manter as funções do Parque de Pituaçu atribuído pelos seus usuários, com uso do Método de Avaliação Contingente - MAC, por intermédio da aplicação de um survey composto de variáveis socioeconômicas e atitudinais. Os usuários do Parque foram questionados sobre as suas disposições a pagar. Para a DAP espontânea $55,2 \%$ dos usuários estavam dispostos a pagar um valor médio de $\mathrm{R} \$ 6,48 /$ mês. A partir da pergunta induzida, onde se construiu um cenário hipotético e temporal, obteve-se um incremento de $8,2 \%$ nas respostas de disposição a pagar, indicando uma DAP média de $\mathrm{R} \$ 7,72$. A análise estatística permitiu identificar que as variáveis atitudinais foram determinantes das DAPs dos usuários. Considerando os benefícios estimados pelo MAC, os valores de disposição a pagar suportaram os custos de operação para manter as funções do Parque. A obtenção de um valor de referência para o Parque Metropolitano de Pituaçu poderá fornecer subsídios ao poder público no sentido de orientar o processo de gestão deste e de outros ativos naturais, servindo ainda de parâmetro para a aplicação de instrumentos econômicos, como forma de compensar economicamente por potenciais danos socioambientais.

Palavras-chave: valoração ambiental; economia dos recursos naturais; Método de Avaliação Contingente; Parque Metropolitano de Pituaçu.

1 Engenheiro Agrônomo. Mestre em Desenvolvimento Sustentável (CDS/UnB). Técnico da Diretoria de Gestão de Unidades de Conservação da Superintendência de Desenvolvimento Florestal e Unidades de Conservação da Secretaria de Meio Ambiente e Recursos Hídricos (SEMARH - BA). gbraz@semarh.ba.gov.br.

2 Doutor em Meio Ambiente e Desenvolvimento Sustentável pelo CDS/UnB, mestre em finanças pela UnB e economista pela UCB. Diretor-Adjunto da Diretoria de Estudos Regionais e Urbanos DIRUR do Instituto de Pesquisa Econômica Aplicada (IPEA - DF). jamota@ipea.gov.br 


\title{
Economic Valuation of recreational areas: a case study of the Pituaçu Metropolitan Park, Salvador, Bahia
}

\begin{abstract}
In urban centers the conception and maintenance of public areas, which are designated to environmental preservation, leisure and recreation, has been a challenge faced by public managers. In an in-expansion area of Salvador, the Metropolitan Park of Pituaçu, with an expressive green area designated to the citizens use, it is under environmental risk indicators and became a fragile natural resource. The aim of this study is to estimate the value to maintain the functions of the Metropolitan Park of Pituaçu, by Contingent Valuation Method (MVC), through an application of a survey, composed of socioeconomic and attitudinal variables. In this case, it is characterized by hypothetical market, where the park users were questioned on their willingness to pay (WTP) for the maintenance of the functions of natural. For the spontaneous WTP, it was observed that 55,2\% of users were willing to pay an average value of $R \$ 6.48$ / month. For the induced question, an increment of 8,2\% in the willingness to pay was reached, showing an average WTP of $R \$ 7.72 /$ month. The statistical analyses identify that the attitudinal variables were determinants to the users WTP. According to the benefits that were estimated by the MAC, the values of willingness to pay supported the operational costs for the maintenance of the Park. Despite the limitations of the method, to obtain a reference value to the Metropolitan Park of Pituaçu can provide subsidies to the public policies to deal with the management process of this natural resource, also working as a parameter to economic instruments application and financial compensation of social and environmental damages.
\end{abstract}

Key words:Environmental valuation; Environmental economics; Contingent Valuation method; Pituaçu Metropolitan Park.

JEL: Q2

\section{Introdução}

As interações existentes entre o homem e o meio ambiente se acentuam em uma perspectiva estritamente utilitária, voltada, notadamente, para a exploração econômica. As nações mundiais estão praticando um modelo de desenvolvimento em que as opções tecnológicas direcionam a um só critério: a obtenção do máximo benefício possível. Nesse aspecto, a crise ambiental porque passa o mundo contemporâneo tem se instaurado, na medida em que se dispõe de recursos ambientais limitados, em contraposição a uma sociedade cada vez mais consumista, cujas aspirações são ilimitadas. Assim, a importância da proteção e preservação do meio ambiente passou a ser palco de inúmeras e exaustivas discussões globais, evidenciando preocupações com o futuro da humani- 
dade. Surge então, o conceito de desenvolvimento sustentável, no qual a inter-relação das atividades econômicas, o meio ambiente e o bemestar social, tanto para as gerações presentes quanto para as futuras, constitui o tripé desse novo paradigma. Essa ótica de desenvolvimento tem sido importante no sentido de alertar sobre a necessidade de garantir e direcionar políticas públicas coerentes com o imperativo da gestão de ativos ambientais, suscitando a necessidade de determinação do valor econômico dos recursos ali existentes e das funções que os mesmos desempenham para a promoção do bem-estar da sociedade.

Inseridas nesse contexto, as áreas de recreação oferecem uma variedade de benefícios, desde aqueles que podem ser valorados em mercados formais, até os considerados intangíveis, que necessitam da aplicação de técnicas para estimar os seus valores. Dessa forma, considerando os benefícios socioambientais que representam, estudos de valoração econômica com vistas a quantificá-los são de extrema importância para subsidiar o processo de gestão das políticas públicas ambientais.

Por meio da disposição a pagar atribuída pelos usuários do Parque Metropolitano de Pituaçu, localizado em Salvador, BA, o presente estudo apresenta os resultados da aplicação do Método de Avaliação Contingente - MAC, como ferramenta de suporte à valoração econômica dos recursos naturais. Analisa ainda, a percepção dos recreacionistas com relação aos principais conflitos que vem interferindo no uso do Parque. Os resultados obtidos servirão, dentre outros, de suporte ao processo de gestão deste e de outros ativos ambientais destinados à preservação/conservação da biodiversidade, lazer e recreação, hedonismo, atividades educacionais e de pesquisa.

\section{Por que atribuir valor aos recursos naturais?}

A necessidade de conceituar e atribuir valor econômico aos recursos naturais, se situa basicamente no fato de que a maioria dos bens e serviços ambientais (parques, locais para recreação e outros recursos naturais públicos ou privados de uso coletivo) e das funções providas ao homem pelo ambiente natural não são transacionados nos mercados convencionais, não existindo assim indicativos de valor. Dessa forma, valorar os recursos naturais e inserir esse montante na análise econômica se constituem, pelo menos, em tentativas de corrigir as tendências negativas do mercado (Romeiro et al. 2001; Mota 2001:37).

O conceito mais usado na valoração de ativos naturais é o de disposição a pagar e refere-se à máxima propensão a pagar que uma pessoa revela ao usar um recurso ambiental, considerando na análise seu limite orçamentário, sua preferência, seu altruísmo, sua renda e outros fatores 
atitudinais. Dessa forma, a relevância da valoração ambiental não se manifesta unicamente na determinação de um preço que expresse o valor econômico do meio ambiente. Assim, Mota (2001: 37), aborda o aspecto da valoração ambiental de modo integrativo e sistêmico, em que são apresentadas questões relacionadas à sustentabilidade biológica e ecológica dos recursos naturais, estratégia de defesa do capital natural, subsídio à gestão ambiental e aspectos econômicos, conforme demonstrado na Tabela 1.

\section{TABELA 1. JUSTIFICATIVAS PARA A VALORAÇÃO ECONÔMICA DOS RECURSOS NATURAIS}

\begin{tabular}{|c|c|}
\hline ASPECTOS & CARACTERÍSTICA \\
\hline \multirow[t]{2}{*}{ Na ótica da sustentabilidade biológica } & $\begin{array}{l}\text { Atuando como função do meio ambiente na cadeia alimentar e na } \\
\text { matriz de suprimentos; }\end{array}$ \\
\hline & Como ação de proteção sustentável dos recursos naturais. \\
\hline \multirow[t]{2}{*}{ Na ótica do enfoque ecológico } & $\begin{array}{l}\text { Como elemento de análise da capacidade de suporte e resiliência } \\
\text { dos recursos naturais em uso; }\end{array}$ \\
\hline & $\begin{array}{l}\text { Como subsídio às ações mitigadoras de degradação dos recursos } \\
\text { naturais. }\end{array}$ \\
\hline \multirow{2}{*}{$\begin{array}{l}\text { Na estratégia de defesa do capital } \\
\text { natural }\end{array}$} & Como forma de manter o capital natural; \\
\hline & $\begin{array}{l}\text { Como função estratégica dos recursos naturais para o } \\
\text { desenvolvimento dos países. }\end{array}$ \\
\hline Como subsídio à gestão ambiental & $\begin{array}{l}\text { Como forma de defesa ética do meio ambiente; } \\
\text { Como suporte à formulação de políticas públicas ambientais. }\end{array}$ \\
\hline \multirow[t]{4}{*}{$\begin{array}{l}\text { Como enfoque nos aspectos } \\
\text { econômicos }\end{array}$} & $\begin{array}{l}\text { Como forma de estimação dos preços dos ativos naturais que não } \\
\text { são cotados no mercado convencional; }\end{array}$ \\
\hline & $\begin{array}{l}\text { Como mecanismo de mensuração monetária das externalidades } \\
\text { oriundas de projetos de investimentos; }\end{array}$ \\
\hline & Como mecanismo de internalização de custos ambientais; \\
\hline & Como método de estimação de indenizações judiciais. \\
\hline
\end{tabular}

FONTE: Adaptado a partir de Mota (2001: 37-65).

O valor econômico total do meio ambiente pode ser obtido a partir da conjunção dos valores de uso, de opção e do valor de existência. $O$ valor de uso está relacionado com as possibilidades presentes e futuras do uso direto e indireto dos recursos naturais, incluindo o uso como fonte de matéria-prima, produtos medicinais, materiais científicos e educacionais, satisfação estética e aventura, vivenciados pessoalmente ou por outras pessoas. $O$ valor de opção ocorre à medida que se procura manter a possibilidade de uso futuro e sustentável do recurso ambiental, deixando evidente a sua preocupação com as gerações atuais e futuras. O usuário de um parque de recreação pode estar disposto a pagar pela opção de usar ou não dos seus recursos futuramente. Já valor de existência, por sua vez, refere-se ao valor manifestado pelos indivíduos sem que ocorra uma relação nem com o uso presente e futuro dos recursos ambientais. As pessoas poderiam manifestar a pagar pela manutenção e preservação das cavernas existentes na Chapada Diamantina mesmo sem conhecê-las, derivando daí a satisfação de bem-estar. 


\section{O Método de Avaliação Contingente - MAC}

Considerando que o valor econômico total do meio ambiente não pode ser mensurado nos mercados formais, algumas técnicas foram desenvolvidas objetivando a revelação dos valores apropriados aos bens e serviços ambientais. Com base na estimativa da disposição a pagar ${ }^{3}$, o Método de Avaliação Contingente - MAC permite mensurar os benefícios proporcionados pelos serviços naturais em função de variáveis socioeconômicas, comportamentais e atitudinais dos seus usuários, em que as pessoas revelam suas preferências, formando assim, um mercado hipotético para o bem ou serviço natural. Desenvolve-se por meio da aplicação de surveys que têm por finalidade captar os desejos, as preocupações, as percepções, os comportamentos e as atitudes das pessoas em relação à preservação de um recurso natural, ou ainda a uma mudança ambiental (Mota 2001:146-7).

Diversos organismos governamentais consideram o MAC como subsídio para as decisões e fundamentação das políticas públicas ambientais. Tem sido utilizado para obter a estimativa de benefícios econômicos e a viabilidade de projetos desenvolvidos por agentes financeiros internacionais, a exemplo do Banco Internacional para a Reconstrução e Desenvolvimento - Bird e o Banco Interamericano de Desenvolvimento BID. Além disso, vem sendo aplicado ainda, para fundamentar as penalidades judiciais quando da compensação de danos causados por desastres ambientais à sociedade, assim como os custos de recuperação dos ecossistemas afetados (May et al. 2000:19; Moraes \& Borger 2000: 504).

O primeiro trabalho desenvolvido com o MAC ocorreu em 1947 e foi escrito pelo então renomado economista Ciriacy-Wantrup. O autor sugeria, com o uso de entrevistas, quantificar os benefícios gerados pela prevenção do processo erosivo do solo, por meio da disposição a pagar, culminando em 1952, com a publicação de um influente livro que abordava o assunto (Hanemman 2000; Mitchell \& Carson 1993). A partir de então, inúmeras investigações com o uso do MAC têm sido registradas, destacando-se assim, por ser o mais aplicado dentre mais de dois mil trabalhos publicados envolvendo métodos de valoração.

No Brasil, diversos estudos têm utilizado a Avaliação Contingente em áreas destinadas à conservação da biodiversidade, às atividades de lazer, recreação e turismo buscando, principalmente, estimar os benefícios proporcionados por estes ativos aos seus usuários, revelar valores de

3 Além da "disposição a pagar" (willingness to pay), o MAC baseia-se também, no conceito de disposição a aceitar (willingness to accept). Assim, permite-se captar dos indivíduos a sua disposição a aceitar a abrir mão de um benefício; disposição a pagar para evitar uma perda e disposição a aceitar compensação por uma perda. 
entrada, como também obter a disposição a pagar para preservar os elementos naturais ou manter as suas funções (Tabela 2).

TABELA 2. APLICAÇÕES DO MÉTODO DE AVALIAÇÃO CONTINGENTE EM ATIVOS NATURAIS

\begin{tabular}{|c|c|c|c|}
\hline ANO & AUTOR & ESTUDO & LOCAL \\
\hline 2003 & Oliveira Filha & Recuperação e preservação - Praias de Niterói & Rio de Janeiro \\
\hline 2003 & Santana & Parque Nacional de Jaú & Amazonas \\
\hline 2003 & Silva & Parque Ambiental Chico Mendes & Rio Branco \\
\hline 2002 & Martins & Praia de Jericoacoara & Ceará \\
\hline 2001 & Hildebrand* ${ }^{*}$ & Parques e Bosques Urbanos & Curitiba \\
\hline 2000 & Mota* & $\begin{array}{l}\text { Pólo Ecológico de Brasília - Jardim Zoológico } \\
\text { Parque Nacional Ấgua Mineral }\end{array}$ & Brasília \\
\hline 2000 & Ferreira & Parque Nacional do Iguaçu & Paraná \\
\hline
\end{tabular}

NOTA: * Aplicaram também o método de custo de viagem.

Tendo em vista basear-se na construção de um mercado hipotético, a aplicação do MAC está sujeito à ocorrência de diversos tipos de vieses, classificados como de origem estratégica do usuário, da informação sobre o ativo ambiental objeto de avaliação, do instrumento de pesquisa, da formulação do mercado hipotético e de protesto em relação algumas informações inseridas na pesquisa. Dessa forma, cabe ao pesquisador identificar e analisar os vieses do método e buscar mecanismos para neutralizálos (Casimiro Filho 1999:64; Mota 2000:132; Mota 2001:156-7; Ortiz 2003:95).

\section{Caracterização da área de estudo}

O Parque Metropolitano de Pituaçu, doravante chamado de PMP, criado por meio do Decreto Estadual No 23.666 de 04 de setembro de 1973, atualmente com 425 hectares, apresenta uma expressiva área verde destinada ao uso público da cidade de Salvador. Localiza-se à margem da Avenida Luiz Viana Filho - Paralela, limitando-se ao Noroeste com o Centro Administrativo da Bahia, ao Leste com a Avenida Otávio Mangabeira - Oceano Atlântico, ao Norte com a Avenida Pinto de Aguiar e ao Sul com a Avenida Jorge Amado. Tem como instituição mantenedora a Companhia de Desenvolvimento Urbano do Estado da Bahia - Conder, vinculada à Secretaria Estadual de Desenvolvimento Urbano - Sedur. A Figura 1 mostra a localização do PMP e sua posição em relação à cidade de Salvador. 
Inserido na bacia hidrográfica do rio das Pedras, tendo como rios principais o Pituaçu e o Cachoeirinha, o PMP vem se definindo como um dos maiores pontos de atração para a recreação e o lazer da população metropolitana. Recebe em torno de 29.400 visitantes mensais que, por ano, representam $13,8 \%$ da população da capital baiana. Neste ativo natural, os usuários encontram um remanescente de Mata Atlântica e uma mata ciliar que contorna o espelho d'água que se configura em forma de trevo, desenhando reentrâncias e pequenas penínsulas. Além das belezas naturais, com todo seu entorno urbanizado, o Parque conta com um museu a céu aberto, detendo um acervo de mais de duas mil esculturas e peças de arte. O Centro de Convivência e Lazer conjugado com a ciclovia, bicicletário e serviços de pedalinho se constituem em variadas opções para os visitantes do local. Palco de atividades culturais, recreativas e educacionais, o Parque também se caracteriza por ser um espaço destinado à realização de ações de educação ambiental e pesquisa científica.

FIGURA 1. LOCALIZAÇÃO DO PARQUE METROPOLITANO DE PITUAÇU, SALVADOR, BA

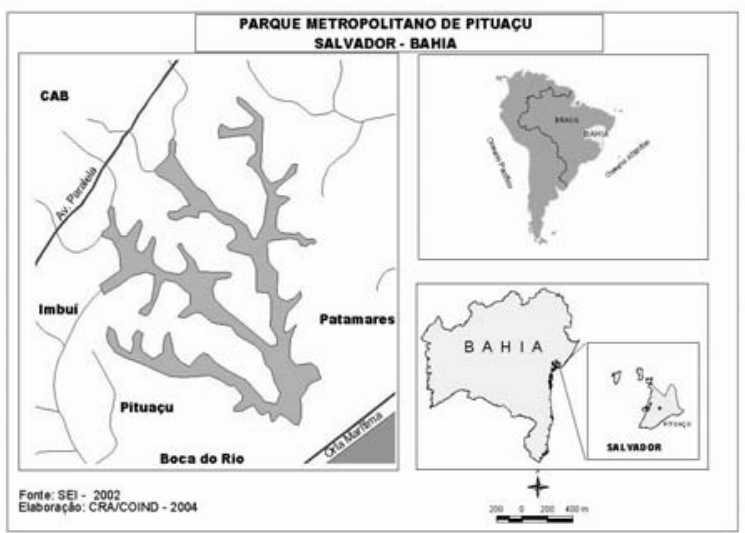

FONTE: Adaptado a partir de SEI, 2002.

Apesar desses aspectos, em função da sua localização, o Parque Metropolitano de Pituaçu se traduz como um ativo natural frágil, estando sujeito a indicativos de risco ambiental: em seu entorno verifica-se a degradação das matas ciliares, a instalação de empreendimentos imobiliários e o avanço da ocupação desordenada do solo, evidenciando problemas de regularização fundiária, além do lançamento de lixo e esgotos. Internamente constata-se a falta de consciência por parte de alguns dos seus usuários no que concerne ao uso e preservação das áreas de lazer e recreação. 


\section{Aspectos metodológicos}

Considerado um mecanismo pioneiro e direto dentro da Avaliação Contingente, a forma para obtenção de valores da disposição a pagar utilizada foi a open-ended. Assim, por meio da aplicação de questões abertas, procurou-se captar a máxima disposição a pagar diretamente ao usuário do ativo natural. Os resultados foram obtidos com a aplicação de surveys nos meses de novembro e dezembro de 2003, a uma amostra de 395 usuários do PMP no próprio local de recreação, estimada com $95 \%$ de confiabilidade e $5 \%$ de erro para suas estimativas.

O survey foi testado antecipadamente com a aplicação de um teste piloto e o grupo de pesquisa ${ }^{4}$ foi devidamente capacitado. As funções do ativo natural e os objetivos da pesquisa foram repassados aos usuários por meio de um boletim informativo. O survey definitivo foi então composto de cinco segmentos: as características socioeconômicas dos usuários; a análise de risco ambiental - conflitos de uso; o comportamento do usuário em relação ao ativo natural; o ponto de vista do usuário em relação ao Parque e, por último, a disposição a pagar do usuário. Após a triagem, os dados dos surveys válidos foram tabulados no Statistical Package for the Social Sciences - SPSS, versão 11.5.

A segunda etapa da metodologia consistiu no desenvolvimento de dois modelos econométricos, originados a partir dos valores de disposição a pagar - DAP 1 e DAP 2, fornecidos pelos usuários, em função das variáveis socioeconômicas e atitudinais, possibilitando assim, estabelecer as respectivas funções de utilidade do PMP e identificar as principais variáveis determinantes das DAPs.

\section{A disposição a pagar dos usuários do PMP}

Mediante a apresentação de um cenário contemplando as funções do PMP e de hipóteses relacionadas ao veículo de pagamento e da sua periodicidade, procurou-se captar a disposição do usuário por pagar ou não para manter as funções do PMP, por meio da seguinte questão:

"Quanto você estaria disposto a pagar mensalmente, em $\mathrm{R} \$$, para manter as funções do PMP?”.

Para captar esse valor foram usadas duas situações:

4 Os surveys foram aplicados com a colaboração de seis acadêmicos da Universidade Católica do Salvador. 
Por meio de uma DAP espontânea: Para os usuários que manifestaram pagar de imediato determinada quantia pela manutenção do PMP. Os valores fornecidos geraram a primeira disposição a pagar, DAP 1.

Por meio de uma DAP induzida: Para os usuários que informaram não estar dispostos a pagar e com o intuito de resgatar as respostas negativas para a DAP, independente do motivo, a partir da construção de um cenário hipotético e temporal ${ }^{5}$, perguntou-se novamente ao usuário:

"Agora, quanto você estaria disposto a pagar mensalmente, em $\mathrm{R} \$$, para manter as funções do PMP?"

As respostas fornecidas, agregadas aos valores da DAP 1, possibilitaram a obtenção de uma nova disposição a pagar, chamada de DAP 2.

\section{Resultados e discussão}

\subsection{Indicativos de risco ambiental}

Os usuários apontam uma série de fatores indicativos da problemática de risco ambiental que tem contribuído para o processo de degradação do PMP. Inicialmente, o desconhecimento por parte dos usuários de como usufruir as instalações e espaços do PMP foi corroborado por um grau de concordância de 93,1\%. O segundo aspecto, cujo percentual de adesão foi de $83,0 \%$, está relacionado ao processo de ocupação irregular situado nas áreas circunvizinhas que tem contribuído para a poluição da lagoa acarretando sério risco na qualidade da água, a ponto de não ser permitido o contato direto com o recurso. $\mathrm{O}$ terceiro fator, mencionado por $81,4 \%$ dos usuários, indicava o uso irrestrito das instalações e espaços do PMP. O aumento dos empreendimentos imobiliários ao redor do PMP e a conseqüente redução da sua área, informada por $63,4 \%$ dos recreacionistas, se caracterizaram como o quarto fator. Por último, cerca de $57 \%$ dos freqüentadores apontaram a ausência de planejamento governamental que forneça subsídio para manter o local como área de lazer e recreação (Figura 2).

5 Considerou-se que dentro de um ano, o estado de manutenção e conservação do PMP estaria superior ao atual, com melhorias na sua infra-estrutura de lazer e recreação, a exemplo da ciclovia, novas vias de acesso, programas de educação ambiental, melhorias na qualidade da água da lagoa, maior controle das ocupações irregulares ao seu redor e incremento na sua programação cultural. 
FIGURA 2. INDICATIVOS DE RISCO AMBIENTAL APONTADOS PELOS USUÁRIOS

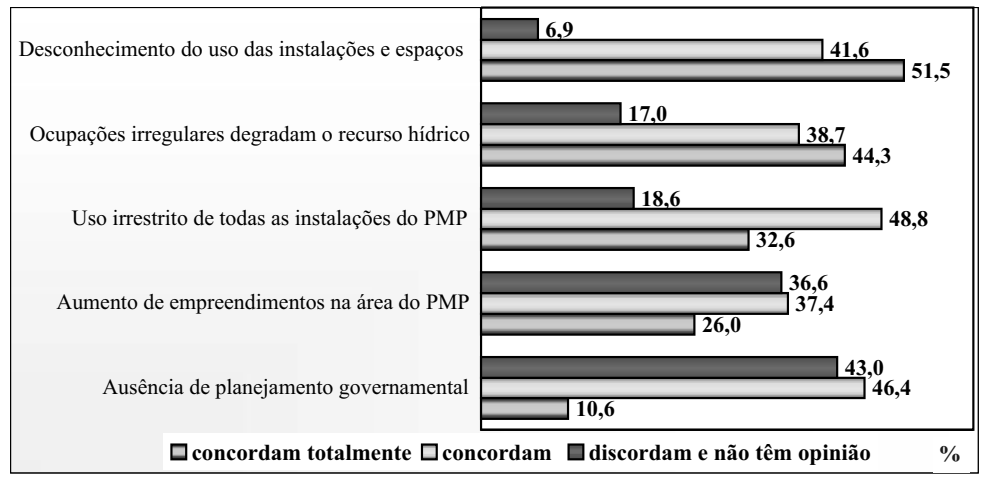

FONTE: Pesquisa de campo dos autores, 2003.

O risco de degradar o recurso pelo uso é uma preocupação evidenciada pelos usuários, em função de três aspectos. O primeiro, com 99,2\%, foi caracterizado pela falta de informações aos visitantes de como poder melhor usar os recursos do PMP sem destruí-los. O segundo relacionava-se ao direito dos visitantes de usarem os espaços do local, de forma que as suas necessidades sejam plenamente satisfeitas, identificado por 83,8\%. Por último, o direito de uso de todas as instalações e espaços do PMP já que a natureza foi criada para suprir as necessidades do homem, foi corroborado por $78,2 \%$ dos recreacionistas (Tabela 3 ).

TABELA 3. INDICATIVOS DE RISCO DE DEGRADAR O PMP POR MEIO DO USO

\begin{tabular}{l|ccc}
\hline \multirow{2}{*}{ RESPOSTAS } & \multicolumn{3}{|c}{ INDICATIVOS DE RISCO DE DEGRADAR o RECURSO PELO USO } \\
\cline { 2 - 4 } & Falta de Orientação & $\begin{array}{l}\text { Satisfação das } \\
\text { Necessidades }\end{array}$ & $\begin{array}{c}\text { Uso de Todos os } \\
\text { Espaços }\end{array}$ \\
\hline Concordam totalmente (\%) & 62,9 & 31,6 & 34,7 \\
Concordam (\%) & 36,3 & 52,2 & 43,5 \\
Discordam totalmente (\%) & 0,5 & 2,1 & 4,5 \\
Discordam (\%) & 0,3 & 13,0 & 16,2 \\
Não têm opinião (\%) & 0,0 & 1,1 & 1,1 \\
\hline
\end{tabular}

FONTE: Pesquisa de campo dos autores, 2003.

\subsection{A Disposição a Pagar}

Agregando-se os resultados obtidos da DAP espontânea e da DAP induzida, verifica-se que os usuários apresentaram $\mathrm{R} \$ 0,50$ como valor 
mínimo e R\$30,00 como máximo. Assim, o valor médio definido pelos recreacionistas para a DAP 2 corresponde a $\mathrm{R} \$ 7,72$ per capita/mês, evidenciando assim, um acréscimo de 19,1\% em relação à DAP espontânea, que foi de $\mathrm{R} \$ 6,48$. Dessa forma, a DAP induzida possibilitou um incremento de $8,2 \%$ no número de usuários que manifestaram disposição a pagar. Conclui-se então, que 63,4\% dos usuários do PMP informaram estar dispostos a pagar um valor mensal pela manutenção das funções do ativo, enquanto $36,6 \%$ continuaram manifestando valores para uma DAP nula (Figura 4).

FIGURA 4. DISPOSIÇÕES A PAGAR PELAS FUNÇÕES DO PMP ATRIBUÍDAS PELOS USUÁRIOS

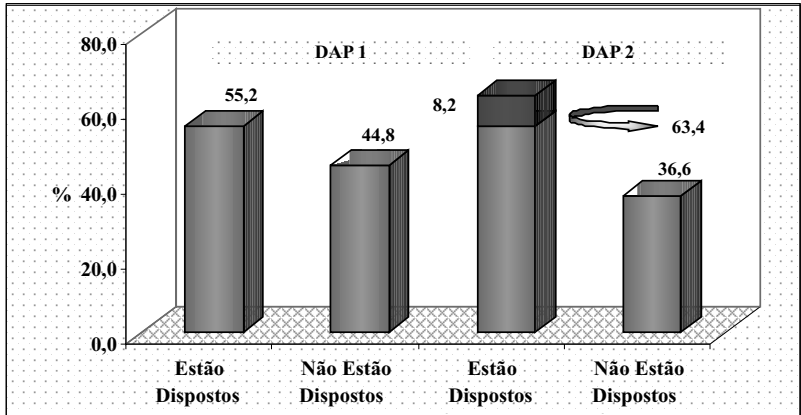

Fonte: Pesquisa de campo dos autores, 2003.

Das justificativas apresentadas pelos usuários que não eliciaram valores pela manutenção das funções do PMP, a maior parte estava ligada a problemas institucionais e financeiros. Assim, 65,3\% atribuíram a responsabilidade ao governo e $18,8 \%$ alegaram motivos econômicos. Os demais $11,6 \%$ apresentaram, dentre outras, as justificativas de que já pagam muitos impostos, e que se deveria incorporar o trabalho voluntário como recompensa. Por último, 4,3\% afirmaram não confiar em organizações particulares de preservação da natureza.

\subsection{As Disposições a Pagar e as variáveis socioeconômicas e atitudinais}

Quando relacionadas as variáveis socioeconômicas dos usuários, podese observar que a renda familiar média dos que manifestaram a sua disposição a pagar, tanto para a DAP 1 como para a DAP 2, situou-se em torno de $\mathrm{R} \$ 1.709,94$, enquanto para aqueles que não estavam dispostos a pagar ficou em $\mathrm{R} \$ 1.687,21$. A variável sexo dos usuários em relação às DAPs não apresentou diferenças significativas quando conside- 
rada a disposição ou não a pagar, situando-se me torno de $50 \%$ para ambos os casos. Considerando-se a faixa etária, observa-se que a idade média dos usuários dispostos a pagar foi equivalente a 34 anos, não diferindo daqueles que apresentaram DAPs nulas. A disposição a pagar versus a escolaridade, por sua vez, indica que os usuários que declararam possuir até o ensino médio e aqueles com curso de doutorado estão mais propensos a disponibilizarem valores para as DAPs. Quanto à procedência ${ }^{6}$, aqueles que se deslocam dos bairros localizados na Região Administrativa de São Caetano estão mais dispostos a pagar para manter as funções do PMP (Tabela 4).

TABELA 4. INDICADORES SOCIOECONÔMICOS DOS USUÁRIOS DO PMP E AS DAPS

\begin{tabular}{l|ccc|c}
\hline & \multicolumn{2}{|c|}{ DAP 1 } & \multicolumn{2}{c}{ DAP 2 } \\
\hline \multicolumn{1}{c}{ INDICADORES } & SIM & NÃo & SIM & NÃo \\
\hline Renda familiar mensal (R\$) & $1.717,88$ & $1.677,98$ & $1.702,05$ & $1.696,44$ \\
Sexo feminino (\%) & 50,5 & 49,5 & 48,6 & 51,4 \\
Sexo masculino (\%) & 50,5 & 49,5 & 51,5 & 48,6 \\
Idade média (anos) & 34,1 & 35,4 & 33,9 & 36,0 \\
Escolaridade & E. Médio e & N. Superior e & Doutorado & Mestrado \\
Procedência & Doutorado & Mestrado & \multirow{2}{*}{ S. Caetano } & \multirow{2}{*}{ S. Ferroviário } \\
\hline
\end{tabular}

FONTE: Pesquisa de campo dos autores, 2003.

À exceção daqueles visitantes que estão indo ao PMP pela primeira vez, os usuários dispostos a pagar informaram freqüentar o ativo em média há 7 anos e realizar 4,6 visitas médias mensais. Aqueles que não atribuíram valores à DAP realizam 3,4 visitas por mês e freqüentam o ativo há pelo menos 7,5 anos. Independente de terem atribuído respostas positivas ou negativas à DAP, os usuários do PMP declararam permanecer em média 3,2 horas visitando o ativo (Figura 5).

6 As procedências dos usuários foram agrupadas segundo as 17 Regiões Administrativas - RAs de Salvador. 
FIGURA 5. DISPOSIÇÃO A PAGAR EM RELAÇÃO AOS ANOS DE FREQÜÊNCIA, VISITAS MENSAIS E PERMANÊNCIA DOS USUÁRIOS NO PMP

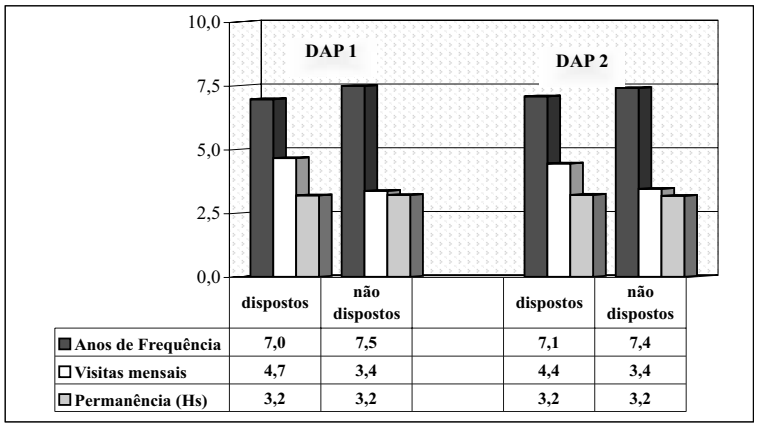

FONTE: Pesquisa de campo dos autores, 2003.

Dos usuários que atribuíram valores às DAPs, 33,1\% para a DAP 1 e $38,5 \%$ para a DAP 2, mencionaram ser a poluição da lagoa juntamente com o lixo, os problemas mais visíveis ao visitarem o ativo. Os que não percebem problemas, juntamente com aqueles que mencionaram "outros", somam 16,5\%, para a DAP 1 e $18,8 \%$ para a DAP 2 (Figura 6).

\section{FIGURA 6. DISPOSIÇÃO A PAGAR EM RELAÇÃO AOS PROBLEMAS DO PMP VERIFICADOS PELOS USUÁRIOS DURANTE A VISITA}

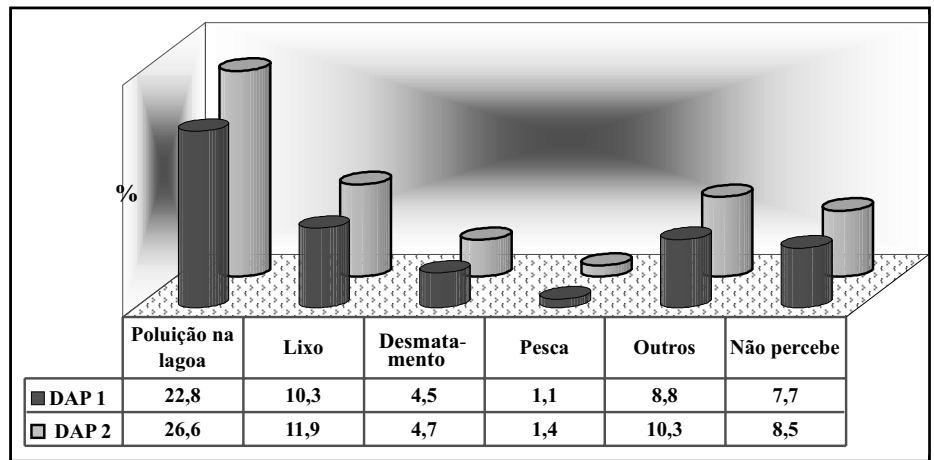

FONTE: Pesquisa de campo dos autores, 2003. 
Em função do sinal de preço atribuído para a manutenção das funções do PMP, as atividades que se mostraram mais significativas quanto à preferência dos usuários foram "andar de bicicleta", "apreciar a natureza" e "fazer caminhada", cujos valores médios das disposições a pagar sinalizaram $R \$ 8,25, R \$ 7,95$ e $R \$ 9,30$, respectivamente (Tabela 5).

TABELA 5. ATIVIDADE PREFERIDA PELOS USUÁRIOS DO PMP EM FUNÇÃO DO SINAL DE PREÇO DA DISPOSIÇÃO A PAGAR

\begin{tabular}{l|c|c|c|c}
\hline \multirow{2}{*}{\multicolumn{1}{c}{ ATIVIDADE PREFERIDA }} & \multicolumn{2}{c|}{ DAP 1 } & \multicolumn{2}{c}{ DAP 2 } \\
\cline { 2 - 5 } & $\%$ & $\mathrm{R} \$$ & $\%$ & $\mathrm{R} \$$ \\
\hline Andar de pedalinho & 2,1 & 8,60 & 2,1 & 8,60 \\
Andar de bicicleta & 16,2 & 8,20 & 19,2 & 8,30 \\
Apreciar a natureza & 15,4 & 8,10 & 16,5 & 7,80 \\
Fazer caminhada & 12,6 & 9,30 & 14,6 & 9,30 \\
Fazer exercícios físicos & 1,9 & 8,90 & 2,1 & 8,10 \\
Freqüentar o restaurante & 0,0 & 0,00 & 0,5 & 12,50 \\
Pescar & 1,1 & 8,80 & 1,3 & 8,00 \\
Visitar esculturas & 0,3 & 10,0 & 0,5 & 7,50 \\
Outras & 5,6 & 9,40 & 6,6 & 8,70 \\
ToTAL & $\mathbf{5 5 , 2}$ & -- & $\mathbf{6 3 , 4}$ & -- \\
\hline
\end{tabular}

FONTE: Pesquisa de campo dos autores, 2003.

\subsection{O valor econômico dos benefícios do PMP}

Por meio da freqüência anual estimada e do sinal de preço atribuído para a DAP espontânea (DAP 1), o montante que maximiza o quanto os recreacionistas estão dispostos a pagar para manter as funções do PMP equivale, por ano, a R \$ 2.286.144,0o. Com a aplicação da DAP induzida, onde se construiu um cenário hipotético e temporal, esse valor passa para $\mathrm{R} \$ 2.723 .616,00$ anualmente, verificando-se assim, um incremento de $19,1 \%$, o que corresponde a $\mathrm{R} \$ 437.472$,oo. Esses valores, caracterizados como benefícios ou excedentes dos usuários, indicam o quanto eles desejam exceder em seus gastos em relação aos seus consumos reais.

Dos modelos analisados, o lin-lin, para os dois casos da DAP, foi o que melhor se ajustou ao conjunto de dados da pesquisa, uma vez que os testes clássicos de Fisher e Student revelaram a escolha das melhores variáveis. Assim, para evidenciar as variações ocorridas nas disposições a pagar dos usuários do PMP, obtiveram-se os seguintes resultados: 


\section{Para a DAP 1:}

$D A P 1=-48,349-1,163_{\text {Anos }}+1,406_{\text {Vis }}+3,048_{\text {Preocup }}+4,331_{\text {Cuidado }}$

\section{Para a DAP 2:}

$D A P 2=-31,534-0,770_{\text {Anos }}+0,939_{\text {Vis }}+1,688_{\text {Preocup }}+3,680_{\text {Cuidado }}$

Onde: Anos = Anos de freqüência dos usuários ao PMP;

Vis = Número de visitas realizadas mensalmente pelos usuários do PMP;

Preocup = Preocupação com os problemas ambientais (poluição do ar, dos rios, desmatamento, lixo);

Cuidado = Cuidado com a lagoa, as paisagens e a preservação das áreas de lazer do PMP.

\subsection{Custos de manutenção do PMP e a Disposição a \\ Pagar}

Os valores de manutenção do PMP foram estimados pela Conder para o ano de 2003 em R\$ 952.721,00. As simulações apresentadas na Tabela 6 representam os valores dos benefícios auferidos pelos usuários do PMP, os quais incluem o break-even point ambiental (ponto de equilíbrio dos benefícios e custos sociais), assim como as sinalizações de taxas para a manutenção das funções do PMP, incluindo as verificadas para a DAP 1 e DAP 2. O usuário contribuindo mensalmente com um valor de $\mathrm{R} \$ 2,70$, permitiria igualar os custos de conservação e preservação de áreas comuns do PMP aos benefícios sociais proporcionados por suas funções.

TABELA 6. SINALIZAÇÃO DE TAXAS DE CONTRIBUIÇÃO MENSAL E BENEFÍCIOS AUFERIDOS/ANO PARA O PMP

\begin{tabular}{c|c}
\hline CONTRIBUIÇÃO MENSAL (R\$) & BENEFíCIOS AUFERIDOS/ANO (R\$) \\
\hline 2,00 & $705.600,00$ \\
$\mathbf{2 , 7 0}-$ break-even point & $\mathbf{9 5 2 . 5 6 0 , 0 0}$ \\
3,00 & $1.058 .400,00$ \\
4,00 & $1.411 .200,00$ \\
5,00 & $1.764 .000,00$ \\
6,00 & $2.116 .800,00$ \\
$\mathbf{6 , 4 8}(\boldsymbol{D A P} 1)$ & $\mathbf{2 . 2 8 6 . 1 4 4 , 0 0}$ \\
7,00 & $2.469 .600,00$ \\
$7,72($ DAP 2) & $\mathbf{2 . 7 2 3 . 6 1 6 , 0 0}$ \\
8,00 & $2.822 .400,00$ \\
\hline
\end{tabular}

FONTE: Elaborado pelos autores. 


\section{Conclusões e recomendações}

Com o estudo, foi possível identificar as características socioeconômicas e as atitudes comportamentais dos usuários em relação ao PMP, bem como as suas disposições a pagar pela manutenção do ativo. A aplicação do Método de Avaliação Contingente permitiu constatar que $63,4 \%$ dos usuários do PMP estão dispostos a pagar pela manutenção das suas funções, com R $\$ 7,72 /$ mês. Dessa forma, a partir da média atribuída, o valor estimado para a manutenção das funções do PMP corresponde a $\mathrm{R}$ \$ 2.723.616,oo por ano. O índice de rejeição à disposição a pagar foi confirmado por $36,6 \%$ dos visitantes, sendo que, desse total, $65,3 \%$ deixou evidente que a manutenção das funções do PMP é uma atribuição do governo.

Foi confirmada a existência de indicativos que refletem uma situação de risco ambiental pela qual passa o PMP, decorrentes, principalmente, do processo de ocupação irregular verificado na área legal do ativo, se caracterizando em um conflito fundiário, juntamente ao processo de especulação imobiliária constatado em seu entorno.

O perfil dos freqüentadores do PMP demonstra que o maior número de visitas ocorre nos finais de semana, notadamente aos domingos, sendo que os usuários que freqüentam aos sábados apresentaram índices mais expressivos na disposição a pagar. Quanto à procedência, a maior participação se dá por usuários provenientes de localidades circunvizinhas, como Boca do Rio, Imbuí e Pituaçu. Com uma idade média de 35 anos, a maior incidência para o grau de escolaridade está representada pelos usuários que estudaram até o Ensino Médio com 58,9\%, porém as maiores participações na disposição a pagar foram verificadas por aqueles que declararam possuir curso de doutorado. A média mensal da renda familiar dos freqüentadores situa-se em torno de $\mathrm{R} \$ 1.700,00$, independente ou não da disposição a pagar.

Quanto à média dos anos de freqüência, constata-se que os usuários visitam o ativo há 7,2 anos, realizando em torno de 4,2 visitas por mês ou uma vez por semana, com uma duração média de 3 horas. A atividade preferida por $29,4 \%$ dos usuários é andar de bicicleta, seguida daqueles que se dirigem ao local para contemplar a natureza com $28,4 \%$ e pela preferência em fazer caminhadas, ressaltada por $21,2 \%$. Quanto aos problemas ambientais detectados pelos usuários durante a sua permanência no Parque, 44,0\% mencionaram a poluição da lagoa.

Segundo as funções obtidas a partir da análise econométrica, as variáveis atitudinais relacionadas aos anos de freqüência, número de visitas mensais, preocupação com os problemas ambientais e, por último, o cuidado com a lagoa, as paisagens e a preservação das áreas de lazer são relevantes na formação das disposições a pagar - DAPs. 
Relacionando-se os custos de manutenção do PMP e as disposições a pagar, foi possível sinalizar valores que permitissem torná-los iguais. Dessa forma, o usuário contribuindo mensalmente com um valor em torno de $\mathrm{R} \$ 2,70$, o que caracteriza o break-even point ambiental, permite-se igualar os custos de manutenção do PMP (conservação e preservação de áreas comuns) aos benefícios sociais proporcionados pelo uso da biodiversidade do ativo.

Torna-se imprescindível uma maior participação de investimentos públicos no PMP como forma de contribuir para a melhoria do seu processo de gestão, os quais busquem direcionar as ações com vistas ao uso sustentável dos recursos ali encontrados. Nesse sentido, são indicadas as recomendações a seguir:

Realizar na ciclovia serviços de manutenção, como também construir ao longo desta, pontos de apoio com instalações básicas, a exemplo de bebedouros e sanitários;

Implementar a sinalização das áreas comuns e das funções do PMP de forma educativa, direcionada aos usuários, composta de linguagem simbólica, lúdica e compreensível, pois a mesma contribuiria para orientar os visitantes quanto a uma melhor conservação dos recursos;

Torna-se necessária a adoção de mecanismos que viabilizem a divulgação dos atrativos e funções do Parque. Isto poderia ser iniciado por meio da distribuição de informativos aos usuários, como também com a comercialização de souvenirs associados à imagem do PMP;

Deve-se incrementar ações ligadas à educação ambiental com os usuários e as comunidades circunvizinhas, com o intuito de esclarecer como melhor utilizar os espaços do PMP, ressaltando a importância das suas funções;

Recomenda-se uma maior atuação da fiscalização como forma de reduzir as ações que venham a degradar os recursos naturais ali existentes. Procurar solucionar os conflitos fundiários, evitando-se assim a incidência de novas ocupações na área legal do Parque;

Promover o fortalecimento de mecanismos de gestão compartilhada com os principais atores sociais ali existentes, a exemplo do Conselho Gestor e da implementação do Zoneamento Ecológico-Econômico, com vistas a disciplinar o uso e ocupação do solo.

Conclui-se então, que os valores estimados pelos usuários para a manutenção das funções do PMP servirão de parâmetros para justificar o aporte de recursos financeiros em projetos que visem à manutenção das funções socioambientais do ativo. Poderão, inclusive, serem utilizados como suporte na sinalização de valores para acesso ao PMP, ou de 
possíveis multas a serem aplicadas aos causadores de danos ambientais, apresentando-se ainda como indicativos na orientação da regularização da malha fundiária do PMP, por meio da determinação de possíveis valores para indenização de ocupações irregulares inseridas no seu interior.

\section{Referências}

CASIMIRO FILHO, F. (1999). "Valoração monetária de amenidades ambientais: algumas considerações.” Teoria e Evidência Econômica 7(13): 53-68.

FERREIRA, S. F. (2000). Valor de uso recreativo do Parque Nacional do Iguaçu - PR: modelo de avaliação contingente. Rio de Janeiro: IPEA. Versão preliminar.

HANEMANN, W. M. (2000). "Valuing the environment through contingent valuation." In STAVINS, R. N. Economics of the environment. 4. ed. Nova Iorque: WW Norton \& Company.

HILDEBRAND, E. (2001). Avaliação econômica dos benefícios gerados pelos parques urbanos: estudo de caso em Curitiba - PR. Curitiba: Tese de Doutorado em Ciências Florestais, Universidade Federal do Paraná.

MARTINS, E. C. (2002). O turismo como alternativa de desenvolvimento sustentável: o caso de Jericoacoara no Ceará. Piracicaba: Tese de Doutorado, Escola Superior de Agricultura Luiz de Queiroz, Universidade de São Paulo.

MAY, P. H. \& VEIGA NETO, F. C. \& POZO, O. V. (2000). Valoração econômica da biodiversidade: estudos de caso no Brasil. Brasília: MMÁ, 193p.

MITCHELL, R. C. \& CARSON, R. T. (1993). Using surveys to value public goods: the contingent valuation method. Washington: Resources for the future. 463p.

MORAES, P. B. L. et al. (2000). "O método de avaliação contingente como instrumento de gestão de projetos ambientais: avaliação da segunda fase do Projeto Tietê." Economia Aplicada 4(3): 503-23.

MOTA, J. A. (2000). Valoração de ativos ambientais como subsídio à decisão pública. Brasília: Tese de Doutorado em Desenvolvimento Sustentável, Centro de Desenvolvimento Sustentável, Universidade de Brasília.

(2001). O valor da natureza: economia e política dos recursos ambientais. Rio de Janeiro: Garamond.

OLIVEIRA FILHA, M. T. A. (2002). Valoração econômica das praias de Niterói situadas na Baía de Guanabara. Rio de Janeiro: Dissertação de Mestrado em Ciências em Planejamento Energético, Universidade Federal do Rio de Janeiro.

ORTIZ, R. A. (2003). "Valoração econômica ambiental." In MAY, P. H. \& LUSTOSA, M. C. \& VINHA, V. (orgs.). Economia do meio ambiente: teoria e prática. Rio de Janeiro: Elsevier, pp. 81-99. 
ROMEIRO, A. R. et al. (2001). Economia do meio ambiente: teoria, políticas e a gestão de espaços regionais. 3. ed. Campinas: Instituto de Economia Unicamp.

SANTANA, R. F. (2003). Valor de existência, uma ferramenta para a gestão de políticas públicas: o caso do Parque Nacional do Jaú. Brasília: Dissertação de Mestrado em Desenvolvimento Sustentável, Centro de Desenvolvimento Sustentável, Universidade de Brasília.

SUPERITENDÊNCIA DE ESTUDOS ECONÔMICOS E SOCIAIS DA BAHIA (2002). (Salvador, BA). Base cartográfica digital do estado da Bahia. Salvador: SEI. 1 CD.

SILVA, R. G. (2003). Valoração do Parque Ambiental "Chico Mendes", Rio Branco - AC: uma aplicação probabilística do método referendum com bidding games. Viçosa: Tese ("Magister Scientiae" em Economia Aplicada), Universidade Federal de Viçosa.

Recebido em: 15 mar. 2006 Aceite em: 28 abr. 2006 